\title{
A phonetic study of the tongue root contrast in Buriat and Ewen
}

\author{
Hijo Kang \\ Stony Brook University \\ hikang@ic.sunysb.edu
}

\author{
Seongyeon Ko \\ Cornell University \\ sk484@cornell.edu
}

\section{LSA Annual Meeting, 7 January 2011, Pittsburgh, PA}

\section{Introduction}

Tongue root (TR) harmony (Ladefoged 1964, Stewart 1967, Lindau 1979, Casali 2008 inter alia), once believed to exist exclusively in West African languages (Stewart 1967), has also been found in many languages in non-Turkic branches of the proposed 'Altaic' family (see Novikova 1960, Ard 1984, Kim 1989, Lr 1996, Zhang 1996 for Tungusic and Qinggertei 1959, Svantesson 1985, Svantesson et al. 2005 for Mongolic). However, compared to the relatively well-studied West African languages (Lindau 1979, Hess 1992, Fulop et al. 1998 for Niger-Congo languages and Jacobson 1980, Guion et al. 2004 for Nilo-Saharan languages), no consensus has been reached on the nature of vowel harmony in Altaic languages, partly due to lack of acoustic studies. As our first step toward investigating the vowels in Altaic languages, this study aims to confirm the TR-based nature of the vowel systems in Buriat (Mongolic) and Ewen (Tungusic). It also attempts to identify the acoustic correlates of the TR contrast in these languages. Given the understudied/endangered status of these Altaic languages, this study contributes to the typological study of TR harmony as well as the field of Altaic linguistics.

\section{Previous studies on tongue root vowel contrast}

Previous studies on the vowel contrast in West African languages have revealed various acoustic factors are relevant to the TR contrast. First of all, F1 has been found to be the most reliable acoustic cue of the TR contrast in e.g., Akan (Hess 1992), Degema (Fulop et al. 1998), Maa (Guion et al. 2004), and Yoruba (Przezdziecki 2005). Advanced tongue root (ATR) vowels are found to have consistently lower F1 than their non-ATR counterparts. Phonation types (breathy voice vs. creaky voice), as suggested by Halle \& Stevens (1969), have also been found to be highly relevant. In particular, Fulop et al. (1998) and Guion et al. (2004) show that ATR vowels have higher 'normalized A1-A2' values (breathy) than their non-ATR counterparts (creaky), although the term breathy/creaky in this context should not be understood in its classic sense (Casali 2008:510). In addition, the bandwidth of F1 has been shown to be higher in non-ATR vowels than in ATR vowels by Hess (1992), Przezdziecki (2005), and Starwalt (2008).

\section{Languages: Western Buriat, Tsongol Buriat, Ewen}

The languages analyzed in this study are two Buriat varieties (Western Buriat and Tsongol-Sartul Buriat) and an Ewen variety, all of which are classified as endangered (Janhunen and Salminen 2000; Moseley 2010). Buriat (Buryat, Buriad) is a Northern Mongolic language spoken by fewer than 400,000 people in Russia (Buryatia), Mongolia, and Inner Mongolia (Skribnik 2003). Western Buriat, spoken by fewer than 50,000 (as estimated by Janhunen and Salminen 2000), has seven vowel phonemes divided into ATR vowels $/ \mathrm{u}$, , , o/, non-ATR vowels / $/$, a, o/, and a neutral vowel /i/. In contrast, 
Eastern Buriat has a six-vowel system due to the merger of short /o/ with /u/ (Poppe 1960, Skribnik 2003, Svantesson et al. 2005). Tsongol-Sartul Buriat, often treated as Southern Buriat (or South Selenge Buriat), is indeed a dialect of Mongolian proper from both historical and linguistic perspectives (Svantesson et al. 2005:142, Skribnik 2003:104). Thus, it is expected to retain the Mongolian seven-vowel system, as in Western Buriat. The number of Tsongol-Sartul speakers is estimated at about 20,000 (Svantesson et al. 2005). Ewen (Even, Eben, Lamut, Orich, Ilqan) is a Northern Tungusic language spoken by only about 7,000 speakers (Russian census 2002) in Eastern Siberia. It has eight short vowel phonemes (Novikova 1960, Lǐ 1996), which are divided into ATR vowels /i, u, ə, $\mathrm{o} /$ vs. non-ATR vowels /I, $v, \mathrm{a}, \mathrm{o} /$. Both Buriat and Ewen have tongue root vowel harmony whereby vowels in a word must agree in terms of [ \pm ATR] (Svantesson et al. 2005, Novikova 1960). Buriat / $\mathbf{i} /$ is neutral and can co-occur with either ATR or nonATR vowels.

\section{Data, Method, etc}

The original data were collected by the Altaic Society of Korea (http://altaireal.snu.ac.kr; cf. Kim et al. 2008). The Western Buriat (WB) data were recorded in Ust'-Ordynskij, Buryatia in January 2007 by a male speaker (born in 1943) of the Ekhirit-Bulagat variety. The Tsongol-Sartul Buriat (TB) data were recorded in Tashir, Buryatia in August 2007 by a female Tsongol speaker (born in 1950). The Ewen data were recorded in Khabarovsk, Russia in February 2006 by a female speaker of Eastern Ewen who was born in a remote village of Magadan Oblast in 1940. After listening to a word in Russian, the consultants were asked to produce the corresponding word in the target language twice in citation form. The recordings were transcribed by the authors in consultation with Bosson (1962) for Buriat and Robbek \& Robbek (2005) for Ewen, respectively. Only short vowels in initial syllables were segmented from the 1,271 (WB), 1,233 (TB), and 899 (Ewen) tokens. The following acoustic features were measured at the middle of each vowel phone (cf. Hertz 1991): the fundamental frequency (F0), the first three formants (F1, F2, F3), the amplitudes of the three formants (A1, A2, A3), the bandwidths of the three formants (B1, B2, B3), the first three harmonics (H1, H2, H3). H1-H2, H1A1, H1-A2, H1-A3, and 'normalized A1-A2' values were calculated as measures of spectral tilt. Each pair of vowels was compared in terms of the measured and calculated acoustic values using one-way ANOVA.

\section{Results}

\begin{tabular}{|c|c|c|c|c|c|c|c|c|c|c|c|c|c|c|c|c|c|}
\hline & F0 & F1 & F2 & F3 & A1 & A2 & A3 & B1 & B2 & B3 & H1 & H2 & H1-H2 & H1-A1 & H1-A2 & H1-A3 & N.A1-A2 \\
\hline WB & $+2 / 3$ & $-\mathbf{3} / 3$ & $+\mathbf{3} / 3$ & & $+3 / 3$ & $-3 / 3$ & & $-3 / 3$ & & $+1 / 3$ & $+3 / 3$ & $+3 / 3$ & & $-1 / 3$ & $+3 / 3$ & & $-3 / 3$ \\
\hline TB & $+3 / 3$ & $-3 / 3$ & & $-1 / 3$ & & $-3 / 3$ & $-3 / 3$ & $-2 / 3$ & $+2 / 3$ & & $+3 / 3$ & $+2 / 3$ & & & $+3 / 3$ & $+3 / 3$ & $-2 / 3$ \\
\hline Ewen & $+2 / 4$ & $-4 / 4$ & & & & & & $-3 / 4$ & & $-2 / 4$ & & & & & $+1 / 4$ & & $+3 / 4$ \\
\hline
\end{tabular}

Table 1 Overall results (+: ATR greater, -: non-ATR greater, $\mathrm{x} / \mathrm{y}$ : significant difference in $\mathrm{x}$ pair(s) out of y pairs) 

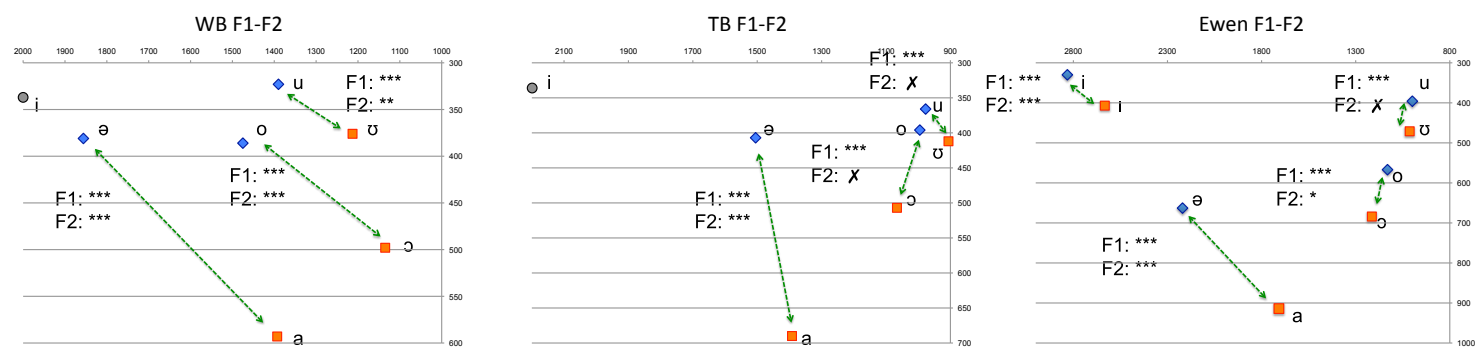

Figure 1 Vowel distribution in F1-F2 space $(* * *: p<001, * *: p<.01, *: p<.05, x: p>.05)$

The overall vowel distributions in F1-F2 space (Figure 1) show that all the three languages have TR-based vowel contrasts. Problematic is /o/ in TB, which seems to have merged into $/ \mathrm{u} /$. The Ewen vowel chart is similar to that of West African languages in that ATR vowels are more peripheral than non-ATR vowels, while the Buriat vowel pairs are diagonally positioned, except for the pair with the problematic /o/ in TB.

Out of all the measured and calculated acoustic features, F1 is the most reliable cue in these two Altaic languages, as it is in West-African languages: ATR vowels have significantly lower F1 than their non-ATR counterparts (for each pair, $p<.01$ ). F2, on the other hand, is not reliable.
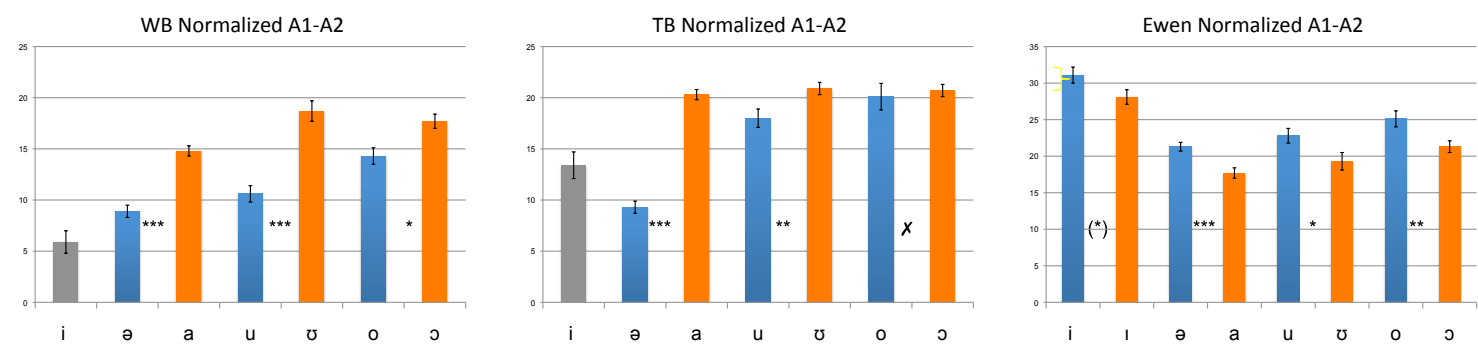

Figure 2 The normalized A1-A2 $\left.{ }^{* * *}: \mathrm{p}<001, * *: \mathrm{p}<.01, *: \mathrm{p}<.05, x: \mathrm{p}>.05\right)$

The normalized A1-A2 was also found to be a reliable cue in all three languages. In Ewen, ATR vowels have higher values than their non-ATR counterparts $(p<.05)$, except for a marginal difference in high front vowels $(\mathrm{p}=.055)$. This is consistent with the results in Fulop et al. (1998) and Guion et al. (2004). Buriat also shows significant difference. However, the direction is the opposite: ATR vowels have lower values than the non-ATR vowels $(\mathrm{p}<.05)$, except for the vowel pair involving the problematic /o/ in the TB speaker. It might be the case either that there is a systematic difference between Mongolic and Tungusic/West-African languages, or that the normalized A1-A2 does not reflect the TR mechanism properly (cf. Starwalt 2008). In either event, further investigation is due, especially in terms of more speakers, more languages, and more control over the data.

Among other acoustic values, B1 was found to be significantly different in many vowel pairs, as in Hess (1992) and Starwalt (2008). The exceptions were the /u/-/ $/$ pair in TB and the /o/-/o/ pair in Ewen. And all the vowel pairs in both varieties of Buriat showed significant differences in $\mathrm{H} 1-\mathrm{A} 2$ values. 


\section{Discussion}

The results of F1 and F2 values confirm that Buriat and Ewen vowel systems are all based on TR contrast, sharing acoustic features with TR contrasts in other languages. The results are also consistent with the X-ray studies of Buriat (Buraeva 1959) and Ewen (Novikova 1960). In addition, the results show a contrast between the two Mongolic varieties: the ongoing merger $/ \mathrm{o} />/ \mathrm{u} /$ in TB vs. the retention of $/ \mathrm{o} /$ in WB. Although TB is originally a Mongolian dialect, it may have been strongly influenced by Eastern Buriat. Lastly, the results may suggest a systematic difference between Mongolic and Tungusic TR contrasts. The two languages in question showed differences in terms of F2 values of back vowels and the normalized A1-A2 values, though these differences must be confirmed by more data and analyses.

Directions for future studies include investigation of other possible acoustic cues such as normalized B1 $(\Delta \mathrm{B} 1)$ and center of gravity (Starwalt 2008), the articulatory characteristics of the vowels, and the effect of prosody (stress, length, and position).

\section{References}

Ard, J. 1984. Vowel harmony in Manchu: A critical overview. Journal of Linguistics 20. 57-80.

Bosson, J. E., 1962. Buriat reader. Bloomington, IN: Indiana University Publications.

Buraeva, I. D., 1959. Zvukovoj sostav burjatskogo jazyka [The sound structure of Buriat]. Ulan-Ude.

Casali, R. F., 2008. ATR harmony in African languages. Language and Linguistic Compass 2. 496-549.

Fulop, S. A., E. Karl, and P. Ladefoged, 1998. An acoustic study of the tongue root contrast in Degema vowels. Phonetica 55. 80-98.

Guion, S. G., M. W. Post, and D. L. Payne, 2004. Phonetic correlates of tongue root vowel contrasts in Maa. Journal of Phonetics 32. 517-542.

Halle, M. and K. N. Stevens, 1969. On the feature "Advanced Tongue Root". MIT Research Laboratory of Electronics Quarterly Progress Report \#94. 209-15.

Hertz, S. R., 1991. Streams, phones, and transitions: toward a phonological and phonetic model of formant timing. Journal of Phonetics 19, 91-109.

Hess, S., 1992. Assimilatory effects in a vowel harmony system: An acoustic analysis of advanced tongue root in Akan. Journal of Phonetics 20. 475-492.

Jacobson, L. C., 1980.Voice-quality harmony in Western Nilotic languages. In R. M. Vago (ed.), Issues in vowel harmony (studies in language companion series, Vol. 6). 183-200. Amsterdam: John Benjamins.

Janhunen, J. and T. Salminen, 2000. UNESCO Red Book on Endangered Languages: Northeast Asia (http://www.helsinki.fi/ tasalmin/nasia_report.html)

Kim, J. 1989. Mancwu Twunggwusu Ceyeuy Moumcohwawa Yenkwu (A Study on Vowel Harmony in the ManchuTungus Languages). Ph.D. Dissertation, Seoul National University.

Kim, J., J. Kwon, D. Ko, Y. Kim, S. Jeon, 2008. Documentation of endangered Altaic languages. Thaehaksa.

Ladefoged, P., 1964. A phonetic study of West African languages. Cambridge: Cambridge University Press.

Lĭ, B. 1996. Tungusic vowel harmony: Description and analysis. Amsterdam: Holland Institute of Generative Linguistics.

Lindau, M., 1979. The feature expanded. Journal of Phonetics 7. 163-176.

Moseley, C., (ed.), 2010. Atlas of the World's Languages in Danger. UNESCO Publishing.

Novikova, K. A., 1960. Očerki dialektov évenskogo jazyka. Ol'skij govor. Moskova: Izd. Akademii Nauk SSSR.

Poppe, N. N., 1960. Buriat Grammar. Bloomington, IN: Indiana University Publications.

Przezdziecki, M. A., 2005. Vowel harmony and coarticulation in three dialects of Yoruba: Phonetics determining phonology. Ph.D. dissertation, Cornell University.

Qinggertai (Chingeltei) 1959. Mongyol kelen-ü bayarin ayalyun-u abiy-a-yin jüi ba üges-ün jüi (Phonology and morphology of the Baarin dialect of Mongolian), ÖMYSS 1959/2. 1-96.

Robbek, V. A. and M. E. Robbek, 2005. Ėven: Ėvensko-russkij slovar'. Novosibirsk: Nauka.

Skribnik, E. K. 2003. Buryat. In Janhunen, Juha (ed.) 2003. The Mongolic Languages. London: Routledge. 102-128.

Starwalt, C. G. A., 2008. The acoustic correlates of ATR harmony in seven- and nine-vowel African languages: A phonetic inquiry into phonological structure. Ph.D. dissertation, The University of Texas, Arlington.

Stewart, J. M., 1967. Tongue root position in Akan vowel harmony. Phonetica 16. 185-204.

Svantesson, J.-O., 1985. Vowel Harmony Shift in Mongolian. Lingua 67. 283-327.

Svantesson, J.-O., A. Tsendina, A. Karlsson, and V. Franzén, 2005. The phonology of Mongolian. Oxford U Press.

Zhang, X., 1996. Vowel systems of the Manchu-Tungus languages of China. Ph.D. dissertation, University of Toronto. 